\title{
Results of cardiac resuscitation in one hundred patients: Effects on acid-base status
}

\author{
BRIAN J. KIRBY \\ M.B.
}

Martin W. MCNicol M.B., M.R.C.P., M.R.C.P.E., M.R.C.P.G.

Cardio-Thoracic Department, Central Middlesex Hospital, Park Royal, London, N.W.10

SINCE the introduction of external cardiac massage the technique and results of cardiac resuscitation have received much attention, but less information is available on the effect of cardiac arrest on respiration and circulation. The authors, who provided a resuscitation service for a general hospital, were particularly interested in these aspects and in thirty-eight of the first 100 patients they obtained an assessment of the respiratory and acid-base disturbances. The technique and results of resuscitation are discussed together with the results of acid-base and respiratory assessment.

\section{Patients}

In the 30-month period between December 1962 and June 1965 cardiac resuscitation was attempted in a total of 100 patients at the Central Middlesex Hospital. The diagnoses and ages of the patients in whom resuscitation was attempted are shown in Table 1 and Fig. 1. Seventy-four were men and twenty-six women. Except where cardiac arrest occurred as a result of diagnostic or therapeutic misadventure, resuscitation was not attempted in patients over 65 years of age.

\section{TABLE 1}

\begin{tabular}{lrrrr}
\hline \multicolumn{1}{c}{ Diagnosis } & No. of & \multicolumn{3}{c}{ Outcome* } \\
\cline { 3 - 6 } patients & & 1 & 2 & 3 \\
\hline Myocardial infarction & 46 & 34 & 8 & 4 \\
Neurological disorders & 13 & 5 & 6 & 2 \\
Poisoning & 5 & 1 & 0 & 4 \\
Pulmonary embolus & 5 & 5 & 0 & 0 \\
Respiratory failure & 8 & 1 & 3 & 4 \\
Operative and post-operative & 10 & 2 & 4 & 4 \\
Injuries & 5 & 3 & 1 & 1 \\
Aneurysm & 2 & 1 & 1 & 0 \\
Rheumatic heart disease & 2 & 1 & 0 & 1 \\
Renal failure & 1 & 0 & 1 & 0 \\
Stokes-Adams' disease & 2 & 0 & 1 & 1 \\
Childbirth & 1 & 0 & 0 & 1 \\
Total & 100 & 53 & 25 & 22 \\
\hline
\end{tabular}

*Group 1: Circulation failed to restart; Group 2: Intermediate-circulation restored but died later; Group 3: Long-term success; left hospital and survived at least 6 months.

\section{Diagnosis and management}

Management was based on diagnosis and initial treatment by the ward staff. The diagnosis was made when there was sudden loss of consciousness with disappearance of the femoral or carotid pulse. The criteria were readily taught and offered little room for misdiagnosis; in practice they proved reliable. All medical, nursing staff and students were instructed in this method of diagnosis and the techniques of mouth-to-mouth respiration and external cardiac massage. Skilled help was summoned by dialling an emergency number whereupon the resuscitation team consisting of the duty anaesthetist, cardiac house physician and one or other of the authors was summoned by the switchboard operator. The anaesthetic registrar and house physician were resident ; the others lived within easy reach of the hospital.

Four 'respiratory boxes' containing a laryngoscope, endotracheal tubes, rubber tubing and reservoir bag with valve, which permitted ventilation via an endotracheal tube from an oxygen supply, were distributed at strategic points in the hospital. A trolley carrying a defibrillator (Cardiac Recorders Ltd), oscilloscope, suction pump and drugs was despatched as soon as an arrest call went out. Initially an a.c. defibrillator was used

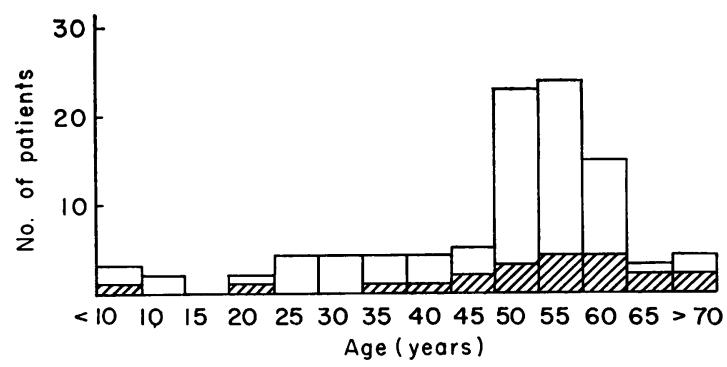

FIG. 1. Age distribution. Cross-hatched columns= long-term survivors. 
but from January 1964 a synchronized d.c. defibrillator has been used.

On arrival the anaesthetist passed an endotracheal tube and thereafter the patient was ventilated with $100 \%$ oxygen. If regurgitation of stomach contents occurred before intubation it was controlled by cricoid compression (Sellick, 1961). A polyethylene catheter was inserted as rapidly as possible by cut-down into the long saphenous vein. Sodium bicarbonate $8 \cdot 4 \%$ (1 mEq/ml), $200 \mathrm{ml}$, was immediately given intravenously. The rhythm was determined on the oscilloscope. If ventricular fibrillation was present immediate defibrillation at $150 \mathrm{~J}$ (Joules) was attempted. If this was unsuccessful or if the result was ephemeral, either propranolol or procainamide was given. When the amplitude of the fibrillation waves was less than $1 \mathrm{mV}$ calcium chloride $20 \% \mathrm{w} / \mathrm{v} 5 \mathrm{ml}$ was administered intravenously. If further attempts to obtain defibrillation were unsuccessful, despite the measures outlined above and after an incremental increase of the discharge energy to $450 \mathrm{~J}$, a further sample of arterial blood was taken to check correction of the acidosis and if this was incomplete further bicarbonate was infused. Resuscitation was abandoned when these measures failed to control ventricular fibrillation.

Asystole, complete heart block and idioventricular rhythm were treated by intravenous isoprenaline sulphate $0.2 \mathrm{mg}$ and calcium chloride $5 \mathrm{ml}$, intravenously. Intracardiac injections were not used. External pacing was always attempted but was rarely successful in these patients; latterly internal pacing was tried with more success.

\section{Management after resuscitation}

Further episodes of arrest were common and all patients were monitored. Recurrent episodes were dealt with as the first episode. Mannitol $20 \%$ was administered intravenously in order to reduce the effect of hypotension on the kidney and to minimize cerebral oedema. Ventilation, when necessary, was carried out with a Cyclator (British Oxygen Company Ltd). Vasopressors (metaraminol, noradrenaline or angiotensin) were used as necessary to maintain the blood pressure. Recently hypothermia has been used if cerebral damage was expected. Heparin was given routinely. Antibiotics were only given if prolonged ventilation was required. Persistent multiple ectopics were treated with propranolol or procainamide. Internal cardiac pacing with a bipolar pacing catheter was used successfully on two patients in whom multiple ectopics could not be suppressed by other means.
Results

\section{Outcome of resuscitation}

Failure $(53 \%)$ : Resuscitation was abandoned without restoration of a spontaneous circulation in fifty-three patients.

Successful (22\%): Long-term survivors in whom a circulation was restored, who left hospital and were alive at least 6 months later-twenty-two patients.

Intermediate $(25 \%)$ : A spontaneous circulation was restored for at least $1 \mathrm{hr}$ but this was not maintained and they died later - twenty-five patients.

The distribution of results by diagnostic categories is shown in Table 1.

Patients with acute myocardial infarction comprised the largest single group (forty-six patients) and had the lowest success rate $(9 \%)$. Other groups had an overall success rate of $26 \%$. The outcome mainly depended on the underlying disease; the long-term success rate was high in patients with a completely reversible disease, for example barbiturate poisoning, but low in those with poor prognosis, for example multiple injuries.

\section{Electrocardiographic findings}

The initial electrocardiogram showed ventricular fibrillation in forty-one; asystole or complete heart block in forty-two. In the remainder a permanent tracing had not been obtained. A delay of many minutes frequently occurred before the electrocardiogram was recorded and the rhythm found may therefore not have been that present at the time of cardiac arrest. The long-term success rate with ventricular fibrillation was three out of forty-one (7\%) and with asystole nine out of fortytwo $(21 \%)$. In the remaining nine long-term survivors the rhythm was not known.

\section{Pacing}

External pacing was attempted in twenty-nine patients with asystole or complete heart block but it was successful in only two patients, both of whom had complete heart block. Internal pacing was used in two patients, one of whom was a long-term survivor.

\section{Complications}

The complications encountered are shown in Table 2. Rib fractures were common but were regarded as serious only when they were so extensive as to require ventilation for stove-in chest. Of the twelve patients with cerebral damage, nine died without leaving hospital; one patient with barbiturate poisoning was presumed to have diffuse cerebral damage but has had an improvement in personality as a result. The remaining two 
TABLE 2

\begin{tabular}{lc}
\hline \multicolumn{1}{c}{ Complications } & $\begin{array}{c}\text { No. of } \\
\text { patients }\end{array}$ \\
\hline Stove-in chest & 4 \\
Cerebral damage & \\
$\quad$ Moderate & 2 \\
Severe & 10 \\
Pneumothorax & 2 \\
Pulmonary oedema & 4 \\
Tracheal stricture & 1 \\
Haemothorax & 1 \\
Haemopericardium & 1 \\
Wound sinus & 1 \\
\hline
\end{tabular}

patients developed hemiparesis; in one it was transient and in the other persistent but he has been able to return to work. Other complications were uncommon. A wound sinus occurred in a patient with stab wounds to the heart. Intractable pulmonary oedema was usually the result of overenthusiastic infusion of sodium bicarbonate and occurred mainly in children.

Artificial ventilation was required in twentythree patients; four for stove-in chest; twelve for respiratory insufficiency either from barbiturate poisoning or pulmonary disease; the remaining seven patients failed to breathe after restoration of the circulation and presumably had cerebral damage as a result of arrest. If after $48 \mathrm{hr}$ artificial ventilation there was no sign of spontaneous respiration an electroencephalogram was performed. If cortical activity was absent then ventilation was stopped. There were ten long-term survivors amongst those ventilated, mainly patients with respiratory insufficiency from poisoning or pulmonary disease.

\section{Duration of massage}

In the failures the mean duration of massage was $51 \mathrm{~min}$ (from 5 to $120 \mathrm{~min}$ ) and in the other groups $20 \mathrm{~min}$ (range 3-110 min). Throughout this time an adequate circulation was clearly maintained and spontaneous respiration after massage was stopped was not infrequent.

\section{Arterial blood sampling and analysis}

Arterial blood was obtained by puncture of either the brachial or femoral artery. This was not easy when there was only a poor pulse but with practice blood could usually be obtained from the femoral artery. In a few patients an arterial catheter was already in place and sampling was carried out through it. Blood samples were taken during external cardiac massage; the timing of the work was such that blood samples were not obtained before injection of sodium bicarbonate. No attempt has been made to relate the results of blood analysis with either the duration of arrest or the amount of bicarbonate given. $\mathrm{pH}$ was measured with a micro-Astrup electrode (Radiometer, Copenhagen), arterial carbon dioxide by a Severinghaus (1956) carbon dioxide electrode and oxygen saturation with a Brinkmann Haemoreflector (Kipp-Zonen, Delft). Plasma bicarbonate was calculated by use of the Hendersen-Hasselbalch equation. Oxygen tension was derived from Dill's dissociation curve which takes account of changes in $\mathrm{pH}$. Lactic acid was determined by an enzymatic method (Scholtz et al., 1959).

\section{Acid-base status (Fig. 2)}

The results are presented on a $\mathrm{PCO}_{2}$-bicarbonate diagram (Campbell, 1962). Thirteen of the patients had a normal blood pH $(7 \cdot 3-7 \cdot 4)$ at the time of sampling. Three patients had a blood $\mathrm{pH}$ above 7•4. The remaining twenty-two patients had a $\mathrm{pH}$ less than $\mathbf{7 \cdot 3}$; in six patients the $\mathbf{p H}$ was below $\mathbf{7 \cdot 0}$. Twenty-three of the thirty-eight patients were underventilated with an arterial carbon dioxide tension greater than $45 \mathrm{mmHg}$. In nine patients underventilation was severe $\left(\mathrm{PCO}_{2}\right.$ over $\left.70 \mathrm{mmHg}\right)$. Overventilation was produced in seven patients, three of whom had a $\mathrm{PCO}_{2}$ less than $30 \mathrm{mmHg}$. In four patients there was a very low plasma bicarbonate (less than $10 \mathrm{mEq} / \mathrm{l}$ ). In twelve patients there was a moderate reduction in plasma bicarbonate $10-20 \mathrm{mEq} / 1)$. Eleven patients had a plasma bicarbonate within the normal range and in eight the plasma bicarbonate was greater than normal; the latter group contained a number of

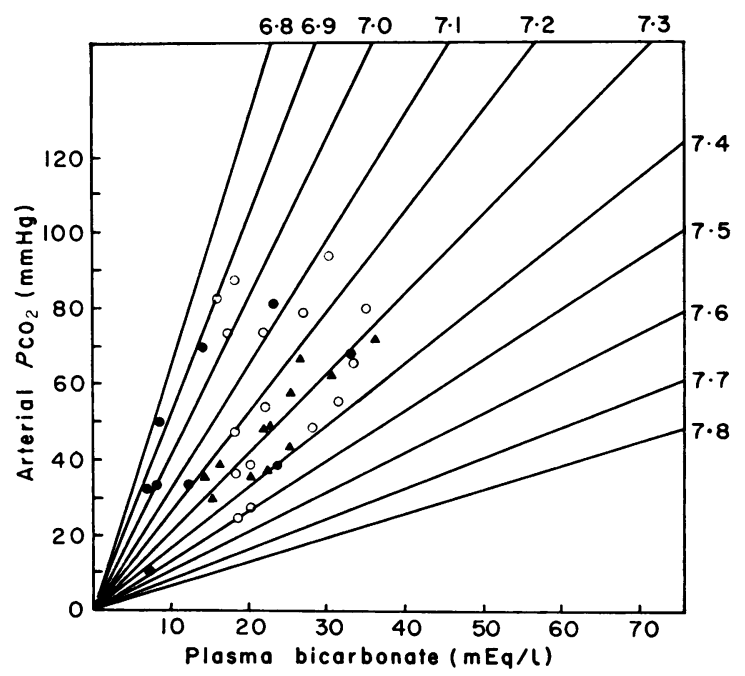

Fig. 2. Acid-base status during external cardiac massage $\bullet$, Group $1 ; 0$, Group $2 ; \stackrel{\Lambda}{ }$, Group 3 . 
patients with chronic respiratory failure. Only three patients were completely in the normal range for $\mathrm{pH}, \mathrm{PCO}_{2}$ and plasma bicarbonate. Normal $\mathrm{pH}$ was produced in some patients with very low plasma bicarbonate by a reduction in $\mathrm{PCO}_{2}$ from vigorous ventilation.

Arterial oxygen (Fig. 3)

Afterial oxygen saturation was above $93 \%$ in nine patients $(25 \%)$. The results for oxygen and carbon dioxide tension are presented on an oxygen-carbon dioxide diagram (Rahn \& Fenn, 1955). As these patients were ventilated with $100 \%$ oxygen inspired oxygen tension was $713 \mathrm{~mm}$ and the respiratory exchange line $(R)$ has been drawn from that point. The horizontal distance between each point and the $R$ line is proportional to the alveolar-arterial oxygen tension difference $\left(\mathrm{A}-\mathrm{aDo}_{2}\right)$. There is an error in calculating oxygen tension from arterial oxygen saturation in those patients with a saturation greater than $94 \%$.

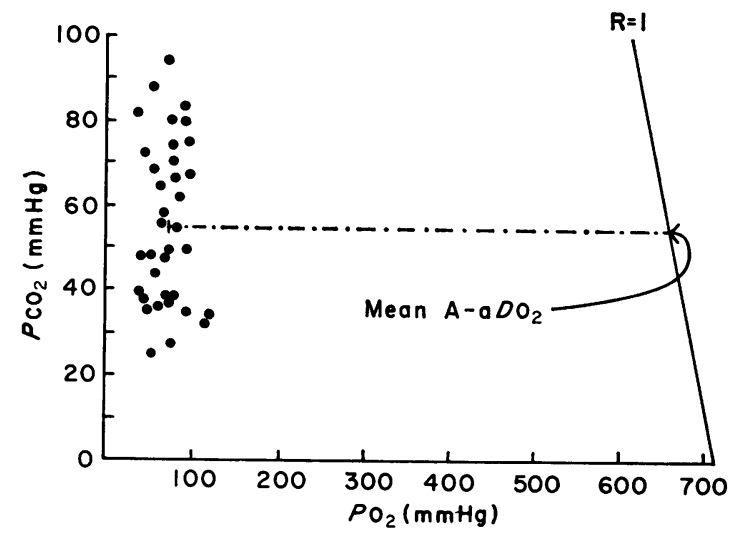

Fig. 3. Oxygen tension during external cardiac massage (thirty-six patients).

\section{Lactic acid (Table 3)}

Lactic acid levels were measured on samples taken after short periods of cardiac arrest before the administration of sympathomimetic drugs in thirteen patients and found to be consistently high.

\section{Discussion}

\section{General}

Variable long-term survival rates have been reported for resuscitation by external cardiac massage, ranging from 6\% (Himmelhoch et al., 1964) to $54 \%$ (Day, 1965). Jude \& Elam (1965), reviewing 290 cases, found an overall success rate of $30 \%$ in the larger series. The success rate in this series may reflect in part the exclusion of older patients. We feel this policy justified in our
TABLE 3

\begin{tabular}{ccc}
\hline $\begin{array}{c}\text { Patient } \\
\text { No. }\end{array}$ & Group & $\begin{array}{c}\text { Lactic acid } \\
(\mathrm{mg} / 100 \mathrm{ml})\end{array}$ \\
\hline 10 & 3 & 22 \\
12 & 2 & 90 \\
44 & 2 & $8 \cdot 4$ \\
48 & 2 & $63 \cdot 5$ \\
50 & 2 & $37 \cdot 1$ \\
53 & 1 & $59 \cdot 6$ \\
59 & 1 & $42 \cdot 2$ \\
60 & 2 & $86 \cdot 5$ \\
75 & 2 & $53 \cdot 4$ \\
83 & 2 & $18 \cdot 4$ \\
86 & 2 & $50 \cdot 75$ \\
96 & 2 & $11 \cdot 7$ \\
98 & 1 & $11 \cdot 5$ \\
\hline
\end{tabular}

working conditions; if facilities were better, more patients could be treated. Procedures have been simplified as treatment must be started by relatively unskilled staff. Diagnosis based on sudden loss of consciousness and absence of pulses in major vessels is readily taught and likely to be remembered in the flurry surrounding a sudden collapse. Ward staff are expected to make the diagnosis, to carry out external cardiac massage and mouth-to-mouth ventilation; they have proved most competent to do this. Attempts at unskilled intubation have led to protracted asphyxia which far outweighed any advantage. Intracardiac injections were not used since they required cessation of external cardiac massage whilst they were attempted. A venous cut-down is simple and well suited to the administration of large quantities of drugs. There is no doubt that drugs given by this route reach the general circulation.

The results of resuscitation varied greatly in different diagnostic groups. The low success rate for myocardial infarction was particularly disappointing. It was expected that arrhythmias in this group would respond well to defibrillation or pacing but this has not been our experience. This may be due to the fact that these patients were not under close observation and that the recognition of premonitory arrhythmias and cardiac arrest itself was often delayed. Diagnosis and treatment in the other groups was often immediate since they were under closer observation. Experience with coronary care units (Day, 1965) suggests that where the coronary patient is similarly closely observed and adequate staff are available, then the results are much better. Casual cardiac monitoring on general medical wards where fully trained staff were not available made little impact on results. 


\section{Aftercare}

The death of more than half of the patients in whom immediate resuscitation had been successful (twenty-five died of the forty-five in whom the heart was restarted), illustrates the difficulties of after care. Results will be poor unless the underlying disease can be effectively treated. Patients with drug overdosage and respiratory failure can do relatively well; those with neurological disorders severe enough to cause cardiac arrest do badly. Patients with myocardial infarction do well if the arrhythmia can be controlled. Drugs often fail to do this and internal pacing may be necessary (Siddons \& Davies, 1963 ; Sowton, Leatham \& Carson, 1964). Multiple cardiac arrests do not necessarily imply a poor prognosis. Three longterm survivors had a total of seven arrests between them.

In addition to the treatment of the underlying disorder, once the heart has been restarted an adequate circulation must be restored. Vasopressors were often unsuccessful in maintaining the blood pressure. Renal failure did not occur in any of the survivors possibly due to the prompt administration of mannitol. Heparin was given routinely since these patients are particularly liable to deep vein thrombosis. At least one patient died from fat embolism and evidence of fat embolism has been found in the lungs of all cases in whom it was sought at autopsy (Dr R. A. B. Drury, personal communication), the effects of which might have been mitigated by giving heparin.

\section{Complications}

In general, long-term survivors regained consciousness within $24 \mathrm{hr}$ although minor degrees of confusion often persisted for several days. Retrograde and post-arrest amnesia were common even in those regaining consciousness immediately. Chest injuries may be reduced by careful attention to technique especially the application of force vertically over the sternum, thereby avoiding shearing strains which are particularly liable to fracture ribs. Artificial ventilation in four patients with stove-in chest did not present any problems. Despite the frequency of rib fractures, rupture of internal organs did not occur. Continued education of staff has done much to reduce the incidence of complications.

\section{Acid-base status}

Our results represent the state of the patient after partial correction of acidosis by infusion of sodium bicarbonate $(200 \mathrm{mEq})$ and ventilation. In sixteen of the patients this was successful in producing a normal or even elevated $\mathrm{pH}$. In the remaining patients acidosis persisted. Two factors were responsible-the metabolic acidosis of cir- culatory arrest and the respiratory acidosis from underventilation. Respiratory factors seemed more important in those patients in whom sodium bicarbonate had been given. Of the twenty-two acidotic patients there was significant underventilation in eighteen $\left(47 \%\right.$ with $\mathrm{PCO}_{2}$ over $50 \mathrm{mmHg}$ ). It is probable that closer attention to ventilation can lower the carbon dioxide tension and so eliminate the respiratory factor in the production of acidosis; three patients had a carbon dioxide tension less than $30 \mathrm{mmHg}$; one of these with a carbon dioxide tension of $10 \mathrm{~mm}$ had completely compensated for a fall in bicarbonate to $7.5 \mathrm{mEq} / 1$. We were surprised at the frequency of underventilation for we were much aware of the need for vigorous ventilation and laid great stress on it.

At the time of sampling infusion of sodium bicarbonate had partially corrected the metabolic acidosis in all but eight patients so that plasma bicarbonate was below $10 \mathrm{mEq} / 1$ in only four patients. Cardiac arrest in this group does not seem to have produced severe metabolic acidosis. Metabolic acidosis would be expected during the period of complete circulatory arrest and would probably increase as the result of a low cardiac output-2 1/min approximately (MacKenzie et al., 1964)-during external cardiac massage. Several reports confirm that metabolic acidosis does follow cardiac arrest in man (Brooks \& Feldman, 1962 ; Stewart, 1964 ; Smith \& Anthonisen, 1965), but there is less information on its severity.

Ledingham \& Norman (1962) found a fall in buffer-base of $1.1 \mathrm{mEq} / \mathrm{l} / \mathrm{min}$ in dogs with circulatory arrest. Data for man are not available. Schemes for bicarbonate therapy based on an assumption of the standard bicarbonate, body weight and duration of arrest have been proposed by Smith \& Anthonisen (1965) and Gilston (1965). In working conditions such as our own often none of these is known. We have therefore adopted an empirical dose of $200 \mathrm{ml}$ of sodium bicarbonate $8.4 \%$ which would provide a $70 \mathrm{~kg}$ man with a rise of plasma bicarbonate of approximately $10 \mathrm{mEq} / \mathrm{l}$. This should be adequate for up to $10 \mathrm{~min}$ circulatory arrest, provided there is no preceding acidosis. Our results suggest that this assumption is justified. Ideally the efficacy of correction of acidosis should be checked before resuscitation is abandoned. Facilities for doing this should be available.

If adequate correction of acidosis is to be obtained with sodium bicarbonate vigorous ventilation is essential for the efficacy of bicarbonate depends on removal of carbon dioxide in the lung.

$$
\begin{aligned}
\mathrm{H}^{+} \mathrm{La}+\mathrm{NaHCO}_{3} \rightleftarrows \mathrm{NaLa}+\mathrm{H}_{2} \mathrm{CO}_{3} \stackrel{\mathrm{SaLa}}{\rightarrow} & +\mathrm{H}_{2} \mathrm{O}+\mathrm{CO}_{2}
\end{aligned}
$$


This reaction proceeds to completion only when the carbon dioxide is removed from the lung by ventilation. Overcorrection is preferable to undercorrection for metabolic acidosis decreases myocardial contractility, perpetuates arrhythmias and decreases the action of vasopressors. There is a theoretical hazard that overventilation may reduce cerebral blood flow, but we feel this is the lesser risk. An initial effort to defibrillate the heart is made as soon as possible but in refractory cases an attempt to completely correct acidosis which may then be followed by successful defibrillation.

\section{Oxygen}

Himmelhoch (1964) and Smith \& Anthonisen (1965) found oxygen saturation to be normal in their patients. In the majority of our patients the saturation was below normal (oxygen saturation less than $93 \%$, in twenty-nine patients-76\%). Oxygen tensions were particularly low relative to the inspired $100 \%$ oxygen and there was a very wide $\mathrm{A}-\mathrm{aDo}_{2}$. Oxygen transfer is not diffusion limited at the high inspired oxygen tension, therefore this difference must be due to ventilationblood flow imbalance for there is no evidence that these patients had an anatomical shunt. It is not surprising that disturbance of ventilation and blood flow should be so abnormal as to produce such a very severe disturbance of oxygen transfer. Cardiac output is low and perfusion must be very abnormal. Positive pressure ventilation produces abnormal distribution of inspired gas. These abnormalities are to some extent overcome by the use of pure oxygen. When air is used for ventilation arterial hypoxaemia is likely and will be increased by diffusion limitation which almost certainly occurs. Early intubation and ventilation with pure oxygen are therefore very important.

\section{Summary}

A cardiac resuscitation service is described. Twenty-one of the first 100 patients treated survived to leave hospital and return to work. Assessment of acid-base status and arterial oxygenation was made in thirty-eight of these patients. The results indicate the need for vigorous ventilation with pure oxygen. In the great majority it was found that infusion of sodium bicarbonate $200 \mathrm{mEq}$ corrected the metabolic acidosis. It is suggested that this empirically derived quantity should be given as a routine especially when there are no facilities for assessing acid-base balance.

\section{Acknowledgments}

We are particularly indebted to the House Physicians and Registrars on our firm who have helped with this work and to all members of the nursing staff without whose help we should have accomplished nothing.

The patients whom we treated have been admitted under the care of all members of the staff of the Central Middlesex Hospital.

Both of the authors are in receipt of a grant from the Medical Research Council which also supports the laboratory in which the blood analyses were carried out. Mrs Madeline Hard assisted in the laboratory work and carried out the lactic acid determinations.

\section{References}

Brooks, D.K. \& Feldman, S.A. (1962) Metabolic acidosis. Anaesthesia, 17, 161.

CAMPBELL, E.J.M. (1962) RIpH. Lancet, i, 681.

DAY, H.W. (1965) Effectiveness of an intensive coronary care area. Amer. J. Cardiol. 15, 51.

GilstON, A. (1965) Clinical and biochemical aspects of cardiac resuscitation. Lancet, ii, 1039.

Himmelhoch, S.R., DekKer, A., Gazzaniga, A.B. \& LIKE, A.A. (1964) Closed chest cardiac resuscitation. New Engl. J. Med. 270, 118.

JUDE, J.R. \& ElAM, J.O. (1965) Fundamentals of Cardio-pulmonary Resuscitation. Blackwell Scientific Publications, Oxford.

Ledingham, I.MCA. \& NoRman, J.N. (1962) Acid-base studies in experimental circulatory arrest. Lancet, ii, 967.

MacKenzie, G.J., Taylor, S.H., McDonald, A.H. \& DONALD, K.W. (1964) Haemodynamic effects of external cardiac compression. Lancet, i, 1342.

RAhN, H. \& FENN, W.O. (1955) A Graphical Analysis of the Respiratory Gas Exchange. American Physiological Society, Washington.

SCHOLZ, R., SCHMITZ, H., BUCHER, TH. \& LAMPEN, J.O. (1959) Uber die Wirking von Mystatin Anf Bäckerhefe. Biochem. Z. 331, 71.

Sellick, B.W. (1961) Cricoid pressure to control regurgitation of stomach contents during induction of anaesthesia. Lancet, ii, 404.

SiDDONS, H. \& DAviES, J.G. (1963) New technique for internal cardiac pacing. Lancet, ii, 1204.

SMITH, H.J. \& ANTHONISEN, N.R. (1965) Results of cardiac resuscitation in 254 patients. Lancet, i, 1027.

Sowton, E., leatham, A. \& Carson, P. (1964) The suppression of arrhythmias by artificial pacemaking. Lancet, ii, 1098.

STEWART, J.S.S. (1964) Management of cardiac arrest with special reference to metabolic acidosis. Brit. med. J. i, 476. 